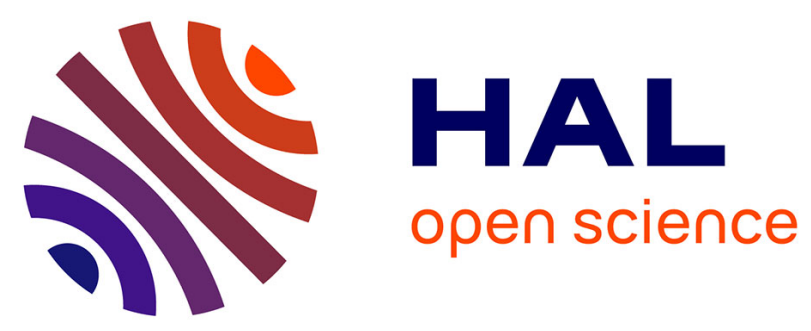

\title{
Interaction networks in a Brazilian cerrado: what changes when you add palynological information to floral visitor data?
}

\author{
Maria Vianna, Cynthia Luz, Astrid Matos Peixoto Kleinert
}

\section{To cite this version:}

Maria Vianna, Cynthia Luz, Astrid Matos Peixoto Kleinert. Interaction networks in a Brazilian cerrado: what changes when you add palynological information to floral visitor data?. Apidologie, 2014, 45 (4), pp.418-430. 10.1007/s13592-013-0256-z . hal-01234735

\section{HAL Id: hal-01234735 \\ https://hal.science/hal-01234735}

Submitted on 27 Nov 2015

HAL is a multi-disciplinary open access archive for the deposit and dissemination of scientific research documents, whether they are published or not. The documents may come from teaching and research institutions in France or abroad, or from public or private research centers.
L'archive ouverte pluridisciplinaire HAL, est destinée au dépôt et à la diffusion de documents scientifiques de niveau recherche, publiés ou non, émanant des établissements d'enseignement et de recherche français ou étrangers, des laboratoires publics ou privés. 


\title{
Interaction networks in a Brazilian cerrado: what changes when you add palynological information to floral visitor data?
}

\author{
Maria Rodrigues Vianna ${ }^{1}$, Cynthia Fernandes Pinto da $\mathrm{LuZ}^{2}$, \\ Astrid de Matos Peixoto Kleinert ${ }^{1}$ \\ ${ }^{1}$ Instituto de Biociências, Departamento de Ecologia, Universidade de São Paulo, Rua do Matão-travessa 14, \\ Butantã, 05508-090, São Paulo, SP, Brazil \\ ${ }^{2}$ Centro de Pesquisa em Plantas Vasculares, Núcleo de Pesquisa em Palinologia, Instituto de Botânica, Av. Miguel \\ Stéfano, 3687 Água Funda, 04045-972, São Paulo, SP, Brazil
}

Received 26 April 2013 - Revised 29 October 2013 - Accepted 14 November 2013

\begin{abstract}
Interaction networks between plants and their floral visitors are often studied with a plant-centered approach, and the results obtained with these data may generate incomplete conclusions on network topology. Thus, we propose to elucidate how biases associated with the approach to data collection can influence the topology of interaction networks by examining species richness, interactions, generalization levels, and nestedness in three interaction matrices: plant-centered, animal-centered, and their combination. The results of the combined data indicate an increase in connectance in relation to animal-centered networks and differences in the mean degree for plants and animals, showing the importance of complementary methods of collecting data to reduce the sampling biases of each isolated method. The nestedness level was most time significant and higher in the animal-centered networks. Our work shows that the apparently specialist behavior of some visitor species may be in part circumvented with the supplementation of plant-centered data with animal-centered data, thereby leading to a result closer to that expected by theory, which predicts a more generalist behavior.
\end{abstract}

\section{pollinator network / topology / plant-animal interaction / palynological data / cerrado}

\section{INTRODUCTION}

The network approach has been widely used in recent years for the study of interactions between plants and floral visitors, focusing on such factors as stability in the face of extinction (Srinivasan et al. 2007) and variation throughout time (Basilio et al. 2006; Medan et al. 2006) and space and its relationship to the sampling effort (Nielsen and Bascompte 2007; Petanidou et al. 2008). None-

Corresponding author: M. R. Vianna, mia.vianna@gmail.com Manuscript editor: Klaus Hartfelder theless, it is not fully understood how plantcentered data collection affects the structure and topology of the interaction networks between plants and pollinators.

In general, we can observe in these networks that an increase in the number of species in a community can decrease its connectance (Jordano 1987) - the proportion of interactions detected within the total possible - suggesting a low level of species generalization (Olesen and Jordano 2002). Furthermore, networks are mostly nested with asymmetrical specialization in which generalist species interact with specialists and generalists and specialists interact mostly with generalists. Each new species that 
enters the system has a higher probability of interacting with those that are more connected (Bascompte et al. 2003).

Considering the generalization level of the species that comprise the system through ecological networks, a large number of specialist species and only few extreme generalists are observed, as characterized by the distribution of the number of interaction partners, which usually follows a pattern of power-law or truncated power-law distributions (Jordano et al. 2003). Based on the properties of truncated power-law distributions, the probability of a given species interacting with $k$ species present in a community decreases as $k$ increases; therefore, extreme generalists would not be expected (Jordano et al. 2006). However, it is possible to find extreme generalists particularly among floral visitors, which might be due to a sampling bias generated by an experimental design that is typically focused on plants rather than floral visitors (Jordano et al. 2006).

In general, bees are considered polylectic generalists that collect pollen from many plant species, sometimes constantly associated with a given plant species for a short period of time and then changing their preference according to previous experiences and perceived new resources (Eickwort and Ginsberg 1980; Waser 1986). Even species considered to be oligolectic (restricted to few genera of related plants; Wcislo and Cane 1996) eventually visit plant species out of their preferred group to obtain other resources, such as nectar and oils (Raw 1974). This incongruence observed between these two foraging strategies has two plausible explanations: (1) generalist visitors may locally restrict their diet, thereby behaving as specialists (Armbruster 2006); or (2) insufficient sampling (Goldwasser and Roughgarden 1997).

Petanidou et al. (2008) demonstrated in a long-term study that biases associated with insufficient sampling tend to decrease, reducing this apparent specialization. However, Nielsen and Bascompte (2007) considered nestedness a measure of generalization that is less prone to an insufficient sampling effort than the number of species and links, and Vázquez and Aizen
(2006) state that increasing such sampling efforts only exacerbates the patterns of extreme specialization and generalization. Because an increase in the level of rare species results in a decrease in asymmetrical specialization (specialists interacting with generalists) and, possibly, in nestedness, the factors affecting specialization should receive more attention.

Some of these topological characteristics are associated with the method used to obtain data on plant-floral visitor interaction networks (Jordano et al. 2006). The approach most commonly used is the observation of visits to the flowers of a community at a given moment (plant-centered approach; Jordano 1987; Olesen and Jordano 2002; Jordano et al. 2003; Bascompte et al. 2003; and others). Another approach is the collection and identification of pollen grains taken by visitors (pollinatorcentered approach; Kanstrup and Olesen 2000; Forup et al. 2008; Bosch et al. 2009). Bosch et al. (2009) indicates that these approaches are complementary, as they reveal different results when combined.

Our study aims to improve the information on the complementarity of pollen and field data with a focus on the Brazilian Cerrado, which is known to have a lower connectance (community generalization is lower) than other Brazilian biomes, at least with regard to social bee species (Biesmeijer et al. 2005). To understand how these biases associated with the method by which data are collected can influence the topology of interaction networks, we tested two predictions. (1) The level of network generalization, as measured through connectance, increases when data obtained by plant-centered methodologies are complemented with animal-centered methodologies. The number of extreme specialists (species that have only one interaction) should decrease due to the identification of possible interactions occurring prior to the capture of the visitor. Therefore, we expect that the networks based on plant-centered data to have a connectance similar to those of the networks based on animal-centered data and that the combination of the two datasets increases connectance. Concomitantly, species generalization, as measured by 
the mean degree, should increase in plant-animal networks at both levels (plants and animals). The mean number of connections of visitor species might be higher in animal-centered versus plant-centered networks due to interactions with plant species that were not directly observed; in contrast, plant-animal networks should have the highest mean number of connections for both plants and animals. (2) The network structure may change depending on the species of the new partners added to the matrix. If these networks have a nested structure, whereby new species tend to interact with the most connected ones, the addition of new interaction partners may increase the level of nestedness.

\section{MATERIALS AND METHODS}

\subsection{Study region}

This study was conducted in an area of the Brazilian cerrado, a vegetation similar to the African savannah and with two well-defined annual seasons, at the Itirapina Ecological Station-SP (IES) located between the municipalities of Itirapina and Brotas $\left(22^{\circ} 15^{\prime} \mathrm{S} ; 47^{\circ} 49^{\prime} \mathrm{W}\right)$. The area was chosen because of the predominance of the vegetation types campo sujo (grassland Cerrado with a few scattered shrubs and small trees) and campo cerrado (a slightly higher density of trees than campo sujo) (Delgado et al. 2004). For each area, three plots of different sizes were selected-100, 400, and $900 \mathrm{~m}^{2}$.

\subsection{Sampling procedure}

One collector performed sampling in the months of January, March, April, July, August, September, October, and December of 2008 and February and March of 2009 on 3 days during each month. On each day, two plots were sampled between 07:00 and 14:00 h. The time in each plot was $1 \mathrm{~h}$, alternating between plots, until reaching $3 \mathrm{~h}$ of data collection in each plot; the additional hour was spent moving between the plots.

The plots were walked in a zigzag pattern until a flowering plant was found and observed for $10 \mathrm{~min}$. During these $10 \mathrm{~min}$, all Apoidea floral visitors that were in contact with stamens or stigmas were collected, immediately killed with ethyl acetate, and placed in individually labeled containers with information including the host plant, time, location, and plot.

The collected visitors were taken to the laboratory and identified to the highest taxonomic resolution possible, with the aid of identification keys and comparisons with previously identified material, or sent to specialists. The material was deposited in the Paulo Nogueira-Neto Entomological Collection, Bee Laboratory, Institute of Biosciences of the University of São Paulo (USP). Vouchers of the visited plants were prepared and later identified by a specialist to the species level and deposited in the Herbarium of the Department of Botany, SPF-IB/USP.

\subsection{Pollen analysis}

The pollen grains used for this analysis were removed from the bodies of the female floral visitors (the grains were collected from the corbicula, scopal hairs, and body) and later subjected to the acetolysis method (Erdtman 1960). If acetolysis was not possible (no accumulation of grains in the corbicula), slides of fresh smears were prepared using Kisser glycerin jelly (Salgado-Labouriau 1973), which was moved over the bodies of the bees to collect any pollen. For each individual, three slides were prepared, and up to 1,000 pollen grains were randomly counted and identified according to Vergeron (1964).

The slides were labeled and deposited in the Pollen Library of the Department of Ecology, IBUSP. A list of species of the IES management plan was used as a regional reference for the identification of the pollen grains, and the palynology specialist (C.F.P. Luz) identified the pollen types based on this list.

As species of the same genus or even the same families exhibit pollen morphological similarities and are easily mistaken, researchers often criticize the identification of pollen grains to the species level (Silva et al. 2012), In addition, other genera exhibit hybridization, and their pollen grains have characteristics that cannot easily be individualized at the species level (Ramalho and Kleinert-Giovannini 1986). Therefore, the pollen grains in the present 
study were identified as pollen types representing the genera present in the study area.

Because it was not possible to identify the pollen grains to the species level, pollen types were associated with the plant genera observed to combine the information from plant-centered and animalcentered data. The pollen grains of some plant species were very similar and flowered during the same period; thus, the pollen types could not be differentiated. In such cases, the information was combined and represented only by the corresponding type in the animal-centered and combined data.

Some individuals exhibited a very small quantity of pollen, and 50 pollen grains were defined as the minimum for inclusion in the construction of networks based on palynological data. Only pollen grains that occurred with a frequency above $10 \%$ in each individual were included (Vergeron 1964). The remaining was treated as a contaminant (resulting from manipulation, storage, or transported by wind) and was not included in the analysis.

\subsection{Data analysis}

Three binary adjacency matrices were constructed for each plot, with the plants in the rows and animal visitors in the columns (Jordano 1987). Only data on the observations of animals visiting plants (plantcentered data) were used in the first matrix, whereas only data on the pollen grains carried by the visitors collected (animal-centered data) were used in the second matrix; both datasets were used in the third matrix. Although the use of three categories is problematic because the combined data are statistically dependent on the plant-centered and animalcentered data, these categories were used to evaluate isolated biases.

\subsection{Complementing data on floral visitors with pollen data increases the level of network generalization}

The network generalization, as measured through connectance, was calculated as suggested by Jordano (1987) and based on the proposal by Yodzis (1980) for trophic webs. Connectance represents the proportion of interactions observed (IO) within the total (IP) possible interactions $(\mathrm{C}=100 * \mathrm{IO} / \mathrm{IP})$, and this index was calculated for each area from the plant-centered, animal-centered, and plant-animal combined matrices. As the plots had different sizes and vegetation types, an ANCOVA (Quinn and Keough 2002) was used to evaluate whether the origin of data affected connectance. The vegetation type and the origin of data were considered categorical blocks; the plot size was the continuous covariate, and connectance values were the continuous response variable.

The generalization level of each species, with the mean number of interaction partners per species, was calculated separately for the plants and floral visitors. An ANCOVA (Quinn and Keough 2002) was used to evaluate whether the origin of data affected the mean number of connections. The vegetation type and the origin of data were considered categorical blocks; the plot size was the continuous covariate, and the mean number of connections was the continuous response variable.

\subsection{Changes in the network structure may occur depending on how new interaction partners are added to the matrix}

The network structure was evaluated with regard to its level of nestedness using the metric NODF (Almeida-Neto et al. 2008). NODF values and their corresponding null models were obtained with the software Aninhado (Guimarães and Guimarães 2006); the null model adopted was $C e$, which maintains marginal sums. An ANCOVA (Quinn and Keough 2002) was used to evaluate whether the origin of the data affects nestedness. The vegetation types and the origin of data were considered categorical explanatory variables; the plot size was the continuous covariate, and the nesting level was the continuous response variable. The data analysis was performed with Statistica 8.0 software (StatSoft 2007).

\section{RESULTS}

Some of the plant species from the genera represented by the same pollen type were grouped into combined networks, as pollen identification was not possible to the species level. For instance, this was the case for Byrsonima coccolobifolia and Byrsonima 
intermedia, represented by the type Byrsonima. Nonetheless, the increase in plant species in this matrix in relation to the plantcentered matrix was significant (Figure 1a; Table I).

For 64 of the 412 floral visitors collected, it was not possible to obtain pollen data for the analysis of plant-centered and combined networks, which resulted in a considerably lower number of visiting species in the animal-centered networks (Figure 1b; Table I). In some cases, the pollen grains of species that were not observed were identified and recorded according to the criteria adopted in the methodology. As the size of the sampled areas was much smaller than the flight capacity of Apoidea (Greenleaf et al. 2007; Tscheulin et al. 2011), these organisms may have visited plants species that did not occur in the study plots.

The number of possible interactions exhibited a different behavior, as this metric is associated with the number of visitors and plants in the network. There were cases in which the number of visiting species decreased in the animal-centered networks compared with the plant-centered networks (due to the exclusion of some of them in the animal-centered networks) such that the number of possible interactions decreased 5$25 \%$; in others, there was an increase between 4 and $40 \%$. When the plantcentered and animal-centered were combined, significant increases of 8-105\% (Figure 1c; Table I) were observed.

The pollen grains of some plant species that were observed were not found in the flower visitors, which might have occurred because some individuals were collected as soon as they had landed on the plant, with no time for pollen manipulation and collection. However, the same result was observed in the combined networks. Despite these limitations, the number of interactions observed increased between 7.5 and $66.6 \%$ in the plant-centered networks and between 62.5 and $140.7 \%$ in the combined networks (Figure 1d; Table I).
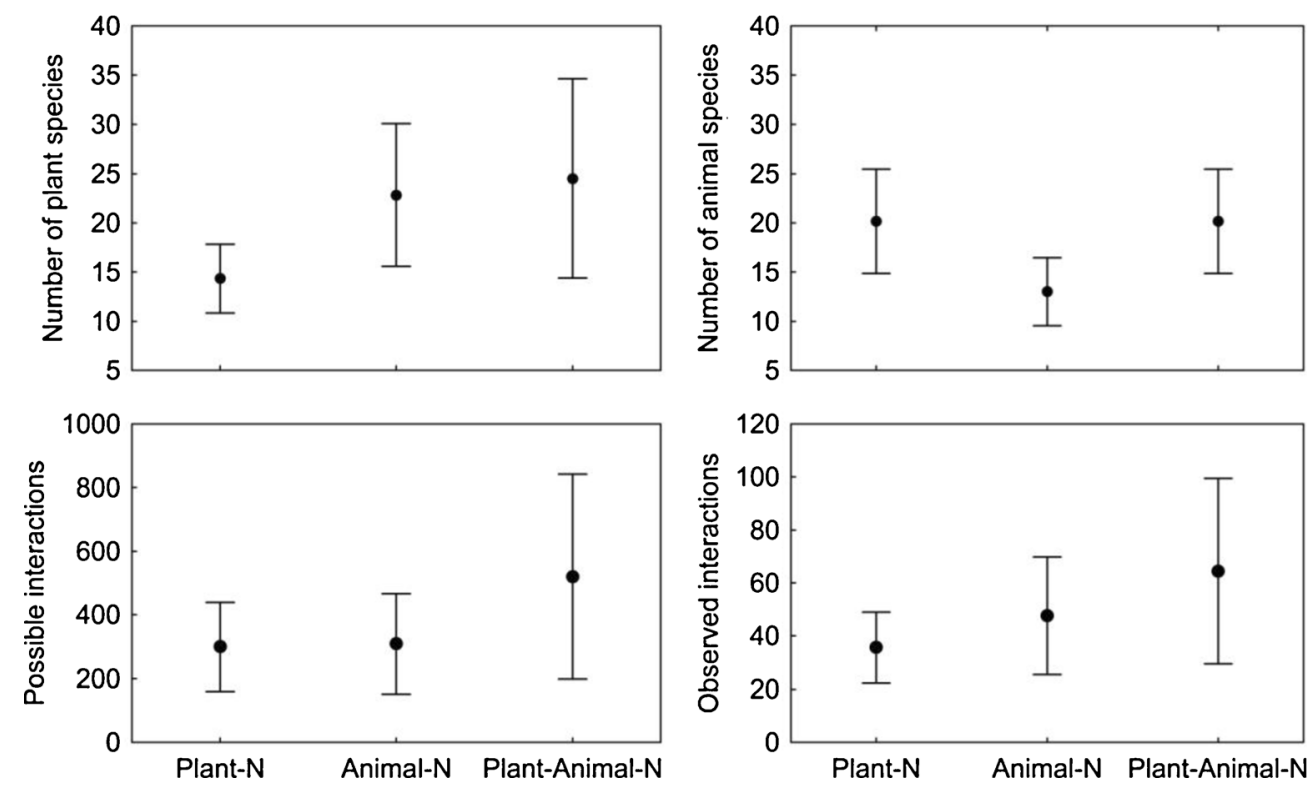

Figure 1. Analysis of binary adjacency matrices obtained with a plant-centered network (Plant-N), animalcentered network (Animal-N), and the two datasets combined (Plant-Animal-N). The dots represent the means, and the upper and lower bars represent the confidence interval (95\%). 
Table I. Influence of the approach used for the construction of interaction matrices (plant-centered networks, $\mathrm{P}$; animal-centered networks, A; combined data, PA) in network metrics analyzed with an ANCOVA.

The third column indicates the direction in the differences revealed by the Tukey's test

\begin{tabular}{llll}
\hline & $F_{(2,13)}$ & $P$ value & Tukey's \\
\hline Number of plant spp & 4.870 & 0.026 & $\mathrm{P}<(\mathrm{A}=\mathrm{PA})$ \\
Number of animal spp & 12.890 & 0.001 & $\mathrm{~A}<(\mathrm{P}=\mathrm{PA})$ \\
Possible interactions & 10.814 & 0.002 & $(\mathrm{P}=\mathrm{A})<\mathrm{PA}$ \\
Observed interactions & 15.680 & $<0.001$ & $(\mathrm{P}=\mathrm{A})<\mathrm{PA}$ \\
Connectance & 16.814 & $<0.001$ & $(\mathrm{P}=\mathrm{PA})<\mathrm{A}$ \\
Plants mean interactions & 2.575 & 0.114 & $\mathrm{~A}<(\mathrm{P}=\mathrm{PA})$ \\
Animals mean interactions & 14.496 & $<0.001$ & $\mathrm{P}<(\mathrm{A}=\mathrm{AP})$ \\
Nestedness level & 11.158 & 0.002 & $(\mathrm{P}=\mathrm{AP})<\mathrm{A}$ \\
\hline
\end{tabular}

3.1. Complementing data of floral visitors with pollen data increases the level of network generalization

The network generalization, as measured by connectance, was higher in the animal-centered networks and equal in the plant-centered and combined networks (Figure 2a; Table I) and might have occurred due to the excess of pollen types found on the animal visitors that did not correspond to the observed plant species. This situation could have sharply increased the mean number of interactions per visitor in the animalcentered and combined networks, though the mean number of interactions per plant decreased in the animal-centered networks and remained

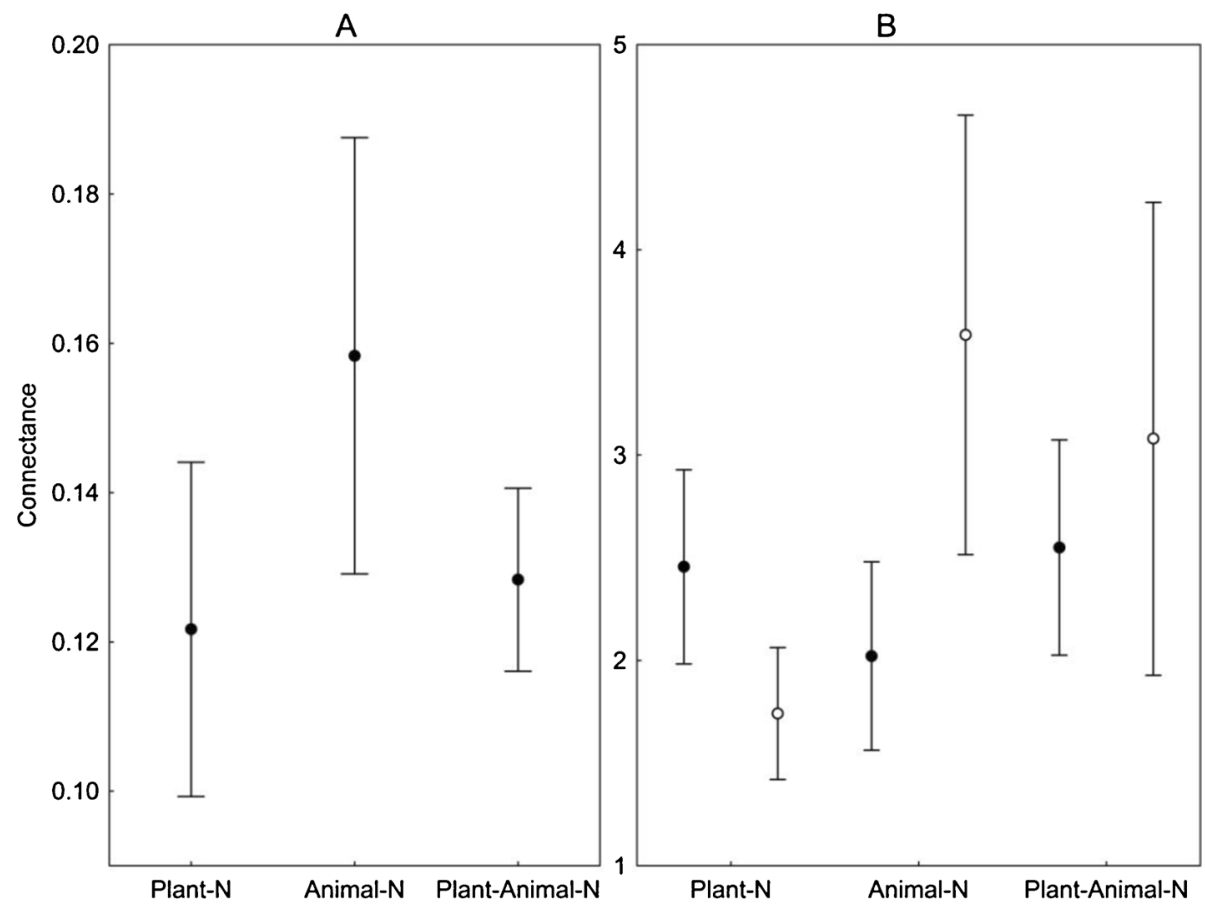

Figure 2. Analysis of binary adjacency matrices obtained with a plant-centered network (Plant-N), animalcentered network (Animal-N), and the two datasets combined (Plant-Animal-N). a Network generalization is represented by connectance; b species generalization is represented by the mean of interactions (the filled circles represent plants, and the open circles represent animals). The dots represent the means, and the upper and lower bars represent the confidence interval (95\%). 
the same in the plant-centered and combined networks (Figure 2b; Table I). As connectance depends on the mean number of interactions, the animal-centered networks increased, and the combined networks decreased. Additionally, when considering the two isolated matrices, an inversion in the level of generalization of the plant and animal species was observed in the plant-centered and animal-centered networks. Plants were found to be more generalists in the plant-centered networks, whereas animals were found to be more generalists in the animalcentered networks.

\subsection{Changes in the network structure may occur depending on how new interaction partners are added to the matrix}

In the plant-centered networks, only the 900$\mathrm{m}^{2}$ plot of campo sujo was significantly nested whereas the $900-\mathrm{m}^{2}$ plots of both vegetation types and the $400-\mathrm{m}^{2}$ plot of campo sujo were considered significantly nested in the animalcentered networks. In the combined networks, the $900-$ and $400-\mathrm{m}^{2}$ plots of both vegetation types were considered significantly nested (Table II).

There were differences in the nestedness levels (Table I), and these differences were observed between the plant-centered and animal-centered networks but not between the plant-centered and the combined networks. This result shows that more interaction types are introduced into the network when different types of data are considered (pollen vs. visitation) (Figure 3).

\section{DISCUSSION}

The most prominent changes in the network metrics were due to the addition of new plant species, which was reflected in the observed and possible interactions, network generalization, and nestedness levels. The impossibility of increasing the taxonomic resolution of pollen grains to the species level (Ramalho and Kleinert-Giovannini 1986; Silva et al. 2012) suggests that the changes detected might even be more prominent. Choosing larger area sizes combined with a more intense sampling effort
Table II. Nestedness (NODF) and significance level $(p)$ of matrices constructed using three approaches (plantcentered networks, Plant-N; animal-centered networks, Animal-N; combined data, Plant-animal-N) for each plot.

\begin{tabular}{lllll}
\hline Matrix & Plot $\left(\mathrm{m}^{2}\right)$ & Vegetation types & NODF & $P$ value \\
\hline Plant-N & 100 & Campo cerrado & 21.30 & 0.370 \\
Plant-N & 400 & Campo cerrado & 14.07 & 0.530 \\
Plant-N & 900 & Campo cerrado & 13.99 & 0.110 \\
Plant-N & 100 & Campo sujo & 15.01 & 0.920 \\
Plant-N & 400 & Campo sujo & 16.43 & 0.200 \\
Plant-N & 900 & Campo sujo & 19.96 & 0.010 \\
Animal-N & 100 & Campo cerrado & 23.74 & 0.690 \\
Animal-N & 400 & Campo cerrado & 21.95 & 0.060 \\
Animal-N & 900 & Campo cerrado & 20.37 & $<0.001$ \\
Animal-N & 100 & Campo sujo & 22.20 & 0.740 \\
Animal-N & 400 & Campo sujo & 26.83 & $<0.001$ \\
Animal-N & 900 & Campo sujo & 22.28 & 0.020 \\
Plant-animal-N & 100 & Campo cerrado & 18.26 & 0.080 \\
Plant-animal-N & 400 & Campo cerrado & 17.43 & 0.050 \\
Plant-animal-N & 900 & Campo cerrado & 16.62 & $<0.001$ \\
Plant-animal-N & 100 & Campo sujo & 18.20 & 0.560 \\
Plant-animal-N & 400 & Campo sujo & 20.09 & $<0.001$ \\
Plant-animal-N & 900 & Campo sujo & 19.79 & $<0.001$ \\
\hline
\end{tabular}




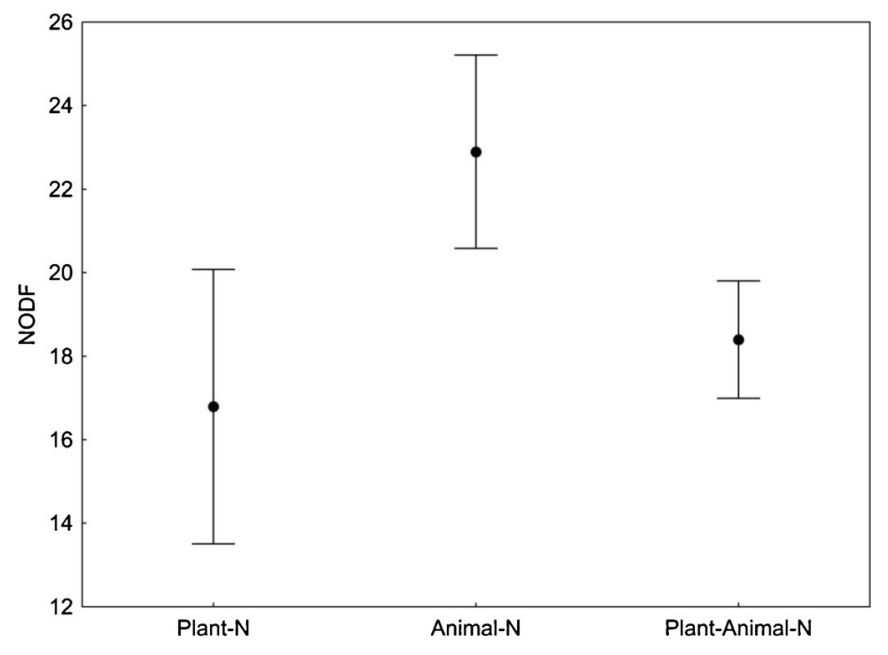

Figure 3. Network structure measured through the nestedness level (NODF) for matrices obtained using a plant-centered network (Plant-N), animal-centered network (Animal-N), and the two datasets combined (PlantAnimal-N). The dots represent means, and the upper and lower bars represent the confidence interval (95\%).

to collect visitors from different vegetation types might decrease the difference between the metrics obtained for the studied networks by increasing the probability of detecting new plant species. Regardless, in systems with high diversity, complementary data on floral visitors with pollen information may help to reduce the sampling effort needed to decrease the bias caused by the usual methodology employed for the construction of networks (Bosch et al. 2009).

In a less diverse Mediterranean ecosystem where 19 plant species represented $99.96 \%$ of flower availability and the period of floral visitor activity tended to be short, Bosch et al. (2009) did not detect differences in the number of animal and plant species when pollen data were combined with floral visitors data. However, as these authors did not include pollen grains that did not belong to the plant species observed, great discrepancies were not observed among the network metrics.

Not finding the pollen grains of observed plants on the body of floral animal visitors or not finding enough pollen grains to be included in the analysis are common events in these systems. It is also common to find pollen grains of plants that are not directly observed on the body of visitors, possibly due to previous visits to plant species in the surroundings of the study plots. Such observations have also been reported by Kanstrup and Olesen (2000) in studies on the interactions in an Equatorial rainforest, Forup et al. (2008) in an analysis on the recovery of ecological interactions, and Bosch et al. (2009) in a study on the complementarity of networks constructed with data based on plant- versus animal-centered methodologies.

\subsection{Network generalization level}

The decrease in connectance when data are combined suggests that the number of nonobserved interactions may be even larger. However, more intensive sampling in larger plots is required to confirm this trend. In megadiverse biomes with high beta diversity, such as the Brazilian Cerrado (Felfili and Felfili 2001; Felfili and Silva 2005; Lima-Ribeiro 2007), an estimation of the number of existing species is only possible with a large number of samples (WM Aguiar 2006; Carvalho et al. 
2008). The representation of these data through rarefaction or accumulation curves shows that this number rarely stabilizes (e.g., Chacoff et al. 2012 in the Monte desert in Argentina, a 4-year study). Even with a large sampling effort, the number of species continues to increase for many taxonomic groups (e.g., Bonaldo et al. 2007; Chacoff et al. 2012). Furthermore, if this occurs for species, it also should occur for possible interactions (Vianna 2010) and, consequently, should occur in an inverse way for connectance (Jordano 1987), as this metric is inversely proportional to those data.

The generalization level of visitor species in the animal-centered and combined networks was higher than that found in the plantcentered networks, indicating that the information based on floral visitors, obtained with the analysis of networks constructed using data on floral visitors tended to underestimate its possible generalization level. According to Jordano et al. (2006) in an analysis of species level distribution, extreme generalist species are commonly found among floral visitors (with the distribution level adjusted to the power law), whereas this is not common among plant species (adjusted to the truncated power law). As suggested by these authors, the reason for these adjustments might be associated with the fact that samplings are usually centered on plants rather than on animal visitors, which is supported by Bosch et al. (2009). Our findings also indicate this when an inversion in the plant and animal visitor species level was observed. However, it was not possible to fit the data to either of these distributions due to the small network size (PR Guimarães et al. 2005).

The inversion in generalization, as measured by the mean degree of interactions of plants and animal species, appears to be one of the most significant consequences of the type of data used for matrix construction (plant- or animalcentered). This occurs because the relative number of rare animals (that interact only once or a few times) is large when centering the collections on plants, thus decreasing the mean degree of interactions, and vice-versa. Therefore, the use of only one of these datasets causes a biased interpretation of the structure of the interactions, mainly because it penalizes the abundance of one side (plants or animals). This bias shows the importance of the analysis of complementary methods of data collection to characterize an interaction network as an alternative to very long-term studies.

Further evidence to support this is the number of observed interactions, which was essentially identical between the plant-centered and animal-centered networks but much higher for the combined data. Some authors hypothesize that preserving the interactions of functional groups is as important as the conservation of certain species (Bascompte et al. 2003; RicoGray and Oliveira 2007). Therefore, if network studies are used as the basis for determining processes or conservation actions, it is necessary to be aware that the majority of the results obtained may be sampling biased.

The plant-centered approach increases the probability of detecting new interactions for each observed individual. In addition, animal visitor species are only observed sporadically, with a frequency that possibly reflects the interaction between the density of that species in the habitat and its floral preferences. Thus, in an adjacency matrix constructed using plantcentered data, many visiting species with a number of interaction partners equal to one are expected, as are higher numbers of floral visitors than plants.

In contrast, the opposite is observed in adjacency matrices constructed with animalcentered data. By identifying possible visits prior to capture, the number of unique interactions for visitors decreases as pollen grains from new plant species are identified. However, the number of unique interactions for plants (possibly rare and not observed) increases, reflecting in the mean degree of species. Additionally, if there are species with high abundance in the habitat, the probability that they have been visited prior to the sampling of visitors is high and possibly proportional to plant's abundance. If this occurs, the number of interactions for this abundant plant species should increase substantially, and it could thus be considered an 
extreme generalist. A consequence of this would be the distribution of frequencies of the level of plant species adjusted to the power-law distribution and of floral visitors to the truncated power-law distribution in networks constructed using animal-centered data.

\subsection{Structural changes}

Although some networks were considered to be significantly nested based on the null model used, the low values of nesting (NODF) might be an indication of a mixed structure, with modules or in a gradient. Indeed, Bosch et al. (2009) found changes in network structure, particularly with regard to modularity. Olesen et al. (2007) detected modules formed by Centridini bees and oil-producing plant species in interaction networks of complete communities. Thus, if there are modules in the structure found in this study, they might be associated with interactions between Malpighiaceae (oilproducing plants) and Centridini visitors (oilcollecting bees), which are clearly related groups (Gottsberger 1986). At the same time, there might be a gradient effect resulting from a sequential replacement of species (Lewinsohn et al. 2006), possibly associated with the high seasonality of the Brazilian cerrado.

Regarding their structure, animal-centered networks are more nested. The NODF metric of nestedness is considered very robust in relation to the number of species: It reaches its maximum level when the columns are perfect subgroups, comparing from left to right and from top to bottom, and the sums from top to bottom are decreasing (Almeida-Neto et al. 2008). The higher connectance, which also expresses the filling of the matrix and the way in which new interaction partners are added in animal-centered networks, might be responsible for this higher value. The lower nestedness in the plant-centered matrix might be caused by the lack of observation in a series of interactions. These interactions might not have been recorded in the field due to few plants in the plots compared with those available in the surroundings. Thus, the combination of both datasets balanced the NODF values found in the combined matrices.

The most accepted hypothesis for the occurrence of nested patterns in interactive communities are (1) passive sampling, which assumes a gradient of abundance (Medan et al. 2007), (2) symmetrical interaction force, which assumes the concept of ecological specialization (Bascompte et al. 2003; Jordano et al. 2006), and (3) phenotypic complementarity, which assumes the concept of morphological specialization (Rezende et al. 2007; Stang et al. 2007). Even if there are differences between some results obtained using plant-centered and animal-centered networks, these are distinct approaches to the same community. Accordingly, there should not be differences in specialization and phenotypical complementarity unless the observed difference is an artifact from sampling biases. Although the number of samples in the animal-centered networks (number of captured visitors) was lower than that of the plant-centered (10 min of observation in flowering individuals), the higher number of interactions observed in the animal-centered indicates that an increased sampling effort would be necessary to detect new interactions.

The approach used for the construction of networks (plant-centered view, animal-centered view, or combined data) alters their generalization level, as measured by connectance, which showed a slight increase for the combined data in relation to the plant-centered approach, most likely due to the increase in connectivity of rare visitor species. However, the generalization of species, as measured by the mean degree, was higher in the animal-centered networks and, consequently, in the combined networks for floral visitors and lower for plants in the animalcentered networks. This inversion in levels clearly demonstrates the relevance of the complementarity of data collection approaches to decrease the sampling biases of each isolated method. The nestedness level was low but significant in many networks-despite their small sizes-and larger in the animal-centered networks.

The increase in connectance of plant species represents an important factor for understanding the persistence ability of species in a habitat, in the 
event of local extinctions of the preferred floral resources. It was also possible to verify that the information at the level of the generalization of visiting species is usually underestimated. Despite the apparently specialist behavior of visitors, it is occasionally not possible to observe the occurrence of interactions due to the low density of certain visitor species. This bias might be partially reduced with complementary data on floral visitors using pollen data. An interface of studies on networks with information on the ecology of visitors will certainly help in future studies for a better understanding of the mechanisms that result in a high frequency of specialist visitors. For example, levels of sociality, characteristics of foraging behavior involving the sequential exploitation of resources, and individual variations regarding their choices, as associated with the level of species generalization, can generate relevant information on the evolution and structure of these interacting communities.

\section{ACKNOWLEDGMENTS}

National Council for Scientific and Technological Development $(\mathrm{CNPq})$ supported this work with a fellowship (Process $n^{\circ}$ 141893/2007-9 to M.R.V.) and with a Research Productivity Fellowship (Process $n^{\circ}$ 301220/2009-3 to C.P.L.). We thank Dr. F A Silveira (UFMG) and Dr. G Mello (UFPR) for the identification of floral visitors, Ms. L Borges (USP) for the identification of plant species, and CO Gridi-Papp for the English translation.

Réseaux d'interactions dans un Cerrado brésilien: qu'est-ce qui change quand vous ajoutez une information palynologique aux données concernant les espèces visitant les fleurs?

Réseaux de pollinisateurs / topologie / interaction plante-animal / données palynologiques / Cerrado

Interaktionsnetzwerke für Bestäuber im CerradoBiom Brasiliens: Was ändert sich, wenn Information zu Pollen in die Analysen einbezogen wird?

Bestäubernetzwerk / Topologie / Tier-PflanzenInteraktion / Palynologiedaten / Cerrado

\section{REFERENCES}

Aguiar, W.M. (2006) Comunidade de abelhas Euglossina (Hymenoptera; Apidae) em remanescentes de mata estacional semidecidual sobre tabuleiro no Estado do Rio de Janeiro. MSc Thesis. Universidade Estadual do Norte Fluminense Darcy Ribeiro, Brazil

Almeida-Neto, M., Guimarães, P.R., Loyola, R.D., Ulrich, W. (2008) A consistent metric for nestedness analysis in ecological systems: reconciling concept and measurement. Oikos 117, 1227-1239

Armbruster, W.S. (2006) Evolutionary and ecological aspects of specialized pollination: views from the Arctic to the Tropics. In: Waser, N.M., Ollerton, J. (eds.) Plant-pollinator interactions: from specialization to generalization, pp. 260-282. University of Chicago Press, Chicago

Bascompte, J., Jordano, P., Melián, C.J., Olesen, J.M. (2003) The nested assembly of plant-animal mutualistic networks. Proc. Natl. Acad. Sci. U S A 100, 9383-9387

Basilio, A.M., Medan, D., Torretta, J.P., Bartoloni, N.J. (2006) A year-long plant-pollinator network. Austral Ecol. 31, 975-983

Biesmeijer, J.C., Slaa, E., Castro, M.S., Viana, B.F., Kleinert, A.M.P., Imperatriz-Fonseca, V.L. (2005) Connectance of Brazilian social bee-food plant networks is influenced by habitat, but not by latitude, altitude or network size. Biota. Neotrop. 5, 1-9 doi:10.1590/S1676-06032005000100010

Bonaldo, A.B., Marques, M.A.L., Pinto-da-Rocha, R., Gardner, T. (2007) Species richness and community structure of arboreal spider assemblages in fragments of three vegetational types at Banhado Grande wet plain, Gravataí River, Rio Grande do Sul, Brazil. Iheringia Sér. Zool. 97, 143-151

Bosch, J., González, A.M.M., Rodrigo, A., Navarro, D. (2009) Plant-pollinator networks: adding the pollinator's perspective. Ecol. Lett. 12, 409-419

Carvalho, F.A., Rodrigues, V.H.P., Kilka, R.V., Siqueira, A.S., Araújo, G.M., Schiavini, I. (2008) Composição florística, riqueza e diversidade de um Cerrado sensu-stricto no sudeste do Estado de Goiás. Biosci. J. (Uberlândia) 24, 64-72

Chacoff, N.P., Vázquez, D.P., Lomáscolo, S.B., Stevani, E.L., Dorado, J., Padrón, B. (2012) Evaluating sampling completeness in a desert plant-pollinator network. J. Anim. Ecol. 81, 190-200

Delgado, J.M., Barbosa, A.F., Silva, C.E., Silva, D.A., Zancheta, D., Gianotti, D., Pinheiro, G.S., et al. (2004) Plano de manejo integrado das Unidades de Conservação de Itirapina. Instituto Florestal do Estado de São Paulo, SP

Eickwort, G.C., Ginsberg, H.S. (1980) Foraging and mating behaviour in Apoidea. Annu. Rev. Entomol. 25, 421-446

Erdtman, G. (1960) The acetolized method: a revised description. Sven. Bot. Tidskr. 54, 561-564 
Felfili, M.C., Felfili, J.M. (2001) Diversidade alfa e beta no Cerrado sensu stricto da Chapada Pratinha, Brasil. Acta Bot. Bras. 15, 243-254

Felfili, J.M., Silva, M.C. (2005) Diversidade alfa e beta no cerrado sensu strictu, Distrito Federal, Goiás, Minas Gerais e Bahia. In: Scariot, A., Souza-Silva, J.C., Felfili, J.M. (eds.) Cerrado: ecologia, biodiversidade e conservação, pp. 141-154. Ministério do Meio Ambiente, Brasília

Forup, M., Henson, K.S.E., Craze, P.G., Memmott, J. (2008) The restoration of ecological interactions: plant-pollinator networks on ancient and restored heathlands. J. Appl. Ecol. 45, 742-752

Goldwasser, L., Roughgarden, J. (1997) Sampling effects and the estimation of food-web properties. Ecology 78, 41-54

Gottsberger, G. (1986) Some pollination strategies in neotropical savannas and forests. Plant Syst. Evol. 152, 29-45

Greenleaf, S.S., Williams, N.M., Winfree, R., Kremen, C. (2007) Bee foraging ranges and their relationship to body size. Oecologia 153, 589-596

Guimarães, P.R., Guimarães, P. (2006) Improving the analyses of nestedness for large sets of matrices. Environ. Model. Software 21, 1512-1513

Guimarães, P.R., Aguiar, M.A.M., Bascompte, J., Jordano, P., Reis, S.F. (2005) Random initial condition in small Barabasi-Albert networks and deviations from the scale-free behavior. Phys. Rev. E 71, 037101. doi:10.1103/PhysRevE.71.037101

Jordano, P. (1987) Patterns of mutualistic interactions in pollination and seed dispersal: connectance, dependence asymmetries, and coevolution. Am. Nat. 129, 657-677

Jordano, P., Bascompte, J., Olesen, J.M. (2003) Invariant properties in coevolutionary networks of plantanimal interactions. Ecol. Lett. 6, 69-81

Jordano, P., Bascompte, J., Olesen, J.M. (2006) The ecological consequences of complex topology and nested structure in pollination webs. In: Waser, N.M., Ollerton, J. (eds.) Specialization and generalization in plant-pollinator interactions, pp. 173-199. University of Chicago Press, Chicago

Kanstrup, J., Olesen, J.M. (2000) Plant-flower visitor interactions in a neotropical rain forest canopy: community structure and generalization level. In: Totland, Ø., Armbruster, W., Fenster, C., Molau, U., Nilsson, L., Olesen, J., Ollerton, J., et al. (eds.) The Scandinavian Association for Pollination Ecology honours Knut Fægri, pp. 33-42. The Norwegian Academy of Science and Letters, Oslo

Lewinsohn, T.M., Loyola, R.D., Prado, P.I. (2006) Matrizes, redes e ordenações: a detecção de estrutura em comunidades interativas. Oecol. Bras. 10, 90-104

Lima-Ribeiro, M.S. (2007) Distribuição espacial de espécies arbóreas em fragmentos de cerrado sentido restrito no Planalto Central Brasileiro-GO. Biociências (Porto Alegre) 15, 160-165
Medan, D., Basilio, A.M., Devoto, M., Bartoloni, N.J., Torretta, J.P., Petanidou, T. (2006) Measuring generalization and connectance in temperate, yearlong active systems. In: Waser, N., Ollerton, J. (eds.) Plant-pollinator interactions: from specialization to generalization, pp. 245-259. University of Chicago Press, Chicago and London

Medan, D., Perazzo, R.P.J., Devoto, M., Burgos, E., Zimmermann, M.G., Ceva, H., Delbue, A.M. (2007) Analysis and assembling of network structure in mutualistic systems. J. Theor. Biol. 246, 510-521

Nielsen, A., Bascompte, J. (2007) Ecological networks, nestedness and sampling effort. J. Ecol. 95, 1134-1141

Olesen, J.M., Jordano, P. (2002) Geographic patterns in plant-pollinator mutualistic networks. Ecology 83, 2416-2424

Olesen, J.M., Bascompte, J., Dupont, Y.L., Jordano, P. (2007) The modularity of pollination networks. Proc. Natl. Acad. Sci. U. S. A. 104, 19891-19896

Petanidou, T., Kallimanis, A.S., Tzanopoulos, J., Sgardelis, S.P., Pantis, J.D. (2008) Long-term observation of a pollination network: fluctuation in species and interactions, relative invariance of network structure and implications for estimates of specialization. Ecol. Lett. 11, 564-575

Quinn, G.P., Keough, M.J. (2002) Experimental design and data analysis for biologists. Cambridge University Press, New York

Ramalho, M., Kleinert-Giovannini, A. (1986) Some aspects of the utilization of pollen analysis in ecological research. Apidologie 17, 159-174

Raw, A. (1974) Preferences of three Osmia species (Hymenoptera). Oikos 25, 54-60

Rezende, E.L., Jordano, P., Bascompte, J. (2007) Effects of phenotypic complementarity and phylogeny on the nested structure of mutualistic networks. Oikos 116, 1919-1929

Rico-Gray, V., Oliveira, P.S. (2007) The ecology and evolution of ant-plant interactions. The University of Chicago Press, Chicago

Salgado-Labouriau, M.L. (1973) Contribuição à Palinologia dos Cerrados. Academia Brasileira de Ciências, Rio de Janeiro

Silva, C.I., Silva, C.M., Santos, F.A.R., Bauermann, S.G. (2012) O Uso da palinologia como ferramenta em estudos sobre ecologia e conservação de polinizadores no Brasil. In: Imperatriz-Fonseca, V.L., Canhos, D.A.L., Alves, D.A., Saraiva, A.M. (eds.) Polinizadores no Brasil: Contribuição e perspectivas para a biodiversidade, uso sustentável, conservação e serviços ambientais. Ed. University of São Paulo, São Paulo

Srinivasan, U.T., Dunne, J.A., Harte, J., Martinez, N.D. (2007) Response of complex food webs to realistic extinction sequences. Ecology 88, 671-682

Stang, M., Klinkhamer, P.G.L., van der Meijden, E. (2007) Assymetric specialization and extinction risk in plant-flower visitor webs: a matter of morphology or abundance? Oecologia 151, 442-453 
StatSoft Inc (2007) STATISTICA (data analysis software system), version 8.0. www.statsoft.com

Tscheulin, T., Neokosmidis, L., Petanidou, T., Settele, J. (2011) Influence of landscape context on the abundance and diversity of bees in Mediterranean olive groves. Bull. Entomol. Res. 101, 557-564

Vázquez, D.P., Aizen, M.A. (2006) Community-wide patterns of specialization in plant-pollinator interactions revealed by null models. In: Waser, N.M., Ollerton, J. (eds.) Specialization and generalization in plant-pollinator interactions, pp. 201-219. University of Chicago Press, Chicago

Vergeron, P. (1964) Interprétation statistique des résultats en matière d'analyse pollinique des miels. Ann. Abeille 7, 349-364
Vianna, M.R. (2010) Fatores que influenciam métricas topológicas de redes de interação entre plantas e visitantes florais: Uma abordagem metodológica. $\mathrm{PhD}$ Thesis. University of São Paulo, São Paulo, Brazil

Waser, N.M. (1986) Flower constancy: definition, cause, and measurement. Am. Nat. 127, 593-603

Wcislo, W.T., Cane, J.H. (1996) Floral resource utilization by solitary bees (Hymenoptera: Apoidea) and exploitation of their stored foods by natural enemies. Annu. Rev. Entomol. 41, 257-286

Yodzis, P. (1980) The connectance of real ecosystems. Nature 284, 544-545 